\title{
Modulated Model Predictive Current Control for PMSM Operating With Three-level NPC Inverter
}

\author{
Qi Wang \\ School of Electrical Engineering \\ Southeast University \\ Nanjing, CHINA \\ Email: qwang.seu@outlook.com
}

\author{
Marco Rivera, Jose A. Riveros \\ Department of Electrical Engineering \\ Universidad de Talca \\ Curico, CHILE \\ Email: marcoriv@utalca.cl
}

\author{
Patrick Wheeler \\ Department of Electrical and \\ Electronic Engineering \\ University of Nottingham \\ Nottingham, U.K
}

Email:Pat.Wheeler@nottingham.ac.uk

\begin{abstract}
In finite control set model predictive control (FCS-MPC) strategy only one basic voltage vector is to be selected in per periodic time, which causes big current ripple as well as the torque ripple of permanent magnet synchronous motor (PMSM). To solve this problem, an improved model predictive control method, named modulated model predictive control (M2PC) is proposed. The proposed control strategy can produce a modulated waveform, which can reduce torque ripple and improve power quality. Simulation results verify that the proposed current controller has a better control performance than the classical FCS-MPC strategy.
\end{abstract}

Keywords-Finite control set model predictive control (FCS$M P C$ ), inverter, neutral-point-clamped (NPC) inverter, predictive control, Modulated Model Predictive Control (M2PC).

\section{INTRODUCTION}

Multi-level converters are widely used in higher voltage range than conventional two-level converter [1]. They can reduce common mode voltages and total harmonic distortion (THD). In multi-level inverters, the three-level inverter has the least number of switches. It can be implemented easily in the technical field of a high voltage. The neutral-point-clamped (NPC) converter is often known as the three-level diode clamped converter which can improve total harmonic distortion and has bigger bandwidth than conventional twolevel converter[2]. It becomes more and more popular in many industrial application fields[3].

Finite control set model predictive control (FCS-MPC) has many advantages, such as simple structure, easy implementation and good multivariable control ability [4]. The FCS-MPC is easily extendible for different industrial applications. It has been widely concerned by academic and industrial communities [5]-[9]. More and more researchers apply MPC strategy for the multilevel converter. In [10], a finite control set model predictive control strategy was used in the five-level active neutral-point-clamped (ANPC) topology inverter for induction machine (IM). In [11], two MPC controllers are proposed for grid-side NPC inverter and generator-side converter respectively. An improved MPC controller for a high power wind energy conversion system using the three-level boost (TLB) converter and NPC inverter was proposed in [11]. In [12], a fast finite switching state MPC was proposed for T-type three-level NPC converter. However, there are still some disadvantages on this control method. The main drawback is that only one basic vector can be selected per periodic time, which causes big current ripple as well as the torque ripple of permanent magnet synchronous motor (PMSM). Another MPC control strategy named deadbeat current predictive control having a fixed switching frequency[13]-[17]. This control strategy only predictive the reference voltage in static coordinate and use the conventional space vector pulse width modulation (SVPWM) algorithm to generate the firing pulses. However, it is very complex in the calculation of switching time[4]. In order to overcome above drawbacks, a novel model predictive control strategy, named modulated model predictive control (M2PC) was proposed [18]-[20]. The M2PC control strategy adds a modulator to generate the duty cycles by selecting two active voltage vectors and zero voltage vectors, and the modulation time of each vector is calculated by minimization of the cost function. In [19], [20], the M2PC strategy was used in a seven-level H-bridge converter. In [21], the M2PC was proposed for brushless doubly fed IM control. In [2], [22], the M2PC was proposed for balancing of the DC-link capacitor voltages and regulating the load currents with a NPC converter.

M2PC for PMSM current control operating with a NPC inverter is proposed in this paper. The M2PC strategy can produce a modulated waveform by operating a cost function minimization algorithm, which can reduce torque ripple of PMSM and improve power quality. A simulation is implemented comparing with the conventional MPC strategy. The simulation results prove the effectiveness of M2PC strategy.

\section{MAthematical Model of THE THREE-LEVEL NPC INVERTER}

The three-level NPC inverter, which is widely used in many industrial application fields [1], [12], [23]-[26], include twelve switches and six clamping diodes.

The structure of three-level NPC inverter is shown in Fig.1. Switches $S_{1 x}$ and $S_{3 x}, S_{2 x}$ and $S_{4 x}$ are complementary states. In the current loop of PMSM control system, the threelevel NPC inverter can produce higher switching frequency to reduce the THD than conventional two-level inverter.

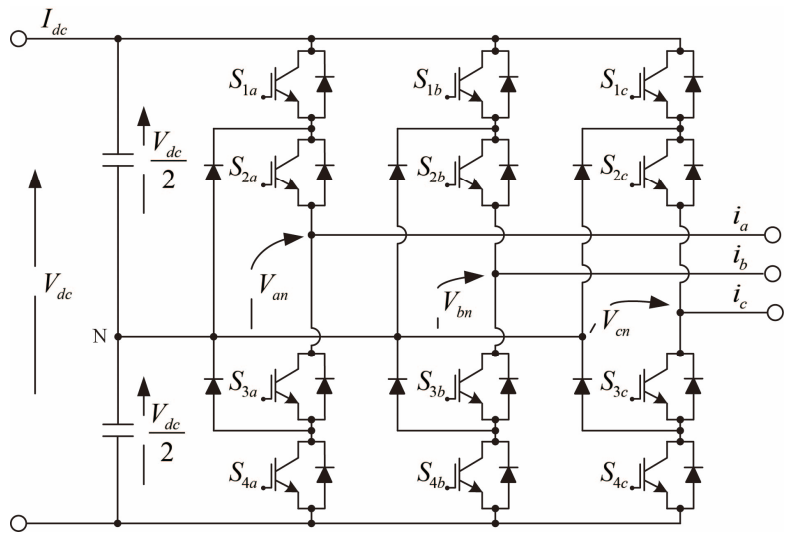

Fig. 1. Three-level neutral-point-clamped (NPC) inverter. 
A total of 27 switching states are available in the threelevel NPC inverter. These switching states can produce 27 voltage vectors in the stationary axis, including 8 redundant voltage vectors and 18 non-redundant vectors. The available voltage vectors of three-level NPC inverter are shown in Fig.2. Switches states and phase voltages of the three-level NPC inverter can be express in table I, where, the $x=a, b, c$.

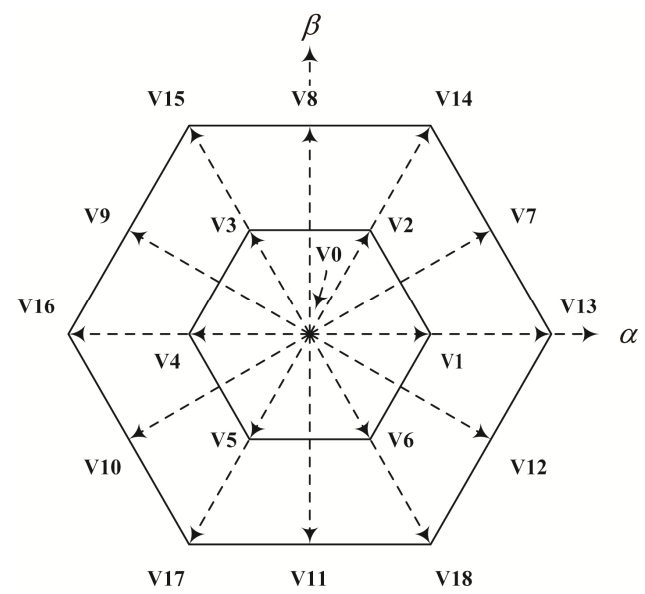

Fig. 2. The available voltage vectors of three-level NPC inverter

TABLE I

SWITCHING STATES AND VOLTAGE OF NPC INVERTER

\begin{tabular}{c|cc|cc|c}
\hline \hline$S_{x}$ & $S_{1 x}$ & $S_{2 x}$ & $S_{3 x}$ & $S_{4 x}$ & $V_{x n}$ \\
\hline 1 & 1 & 1 & 0 & 0 & $V_{d c}$ \\
0 & 0 & 1 & 1 & 0 & $V_{d c} / 2$ \\
-1 & 0 & 0 & 1 & 1 & 0 \\
\hline \hline
\end{tabular}

\section{Conventional Model Predictive Current Control} FOR PMSM

\section{A. PMSM Mathematical Model}

The $d-q$ axis mathematical model of permanent magnet synchronous motor is shown as follows:

$$
\left\{\begin{array}{l}
u_{d}=R_{s} i_{d}+L_{d} \frac{d i_{d}}{d t}-L_{q} \omega_{e} i_{q} \\
u_{q}=R_{s} i_{q}+L_{q} \frac{d i_{q}}{d t}+L_{d} \omega_{e} i_{d}+\psi \omega_{e}
\end{array}\right.
$$

Where, $u_{d}$ and $u_{q}$ represent the d-q-axis voltages; $\omega_{e}$ is the electrical rotor speed of PMSM; $i_{d}$ and $i_{q}$ represent the dq-axis currents; $\psi$ is the flux linkage of permanent magnet; $L_{d}$ and $L_{q}$ are the d-q-axis inductances and $R_{s}$ is the stator resistance.

The d-axis inductance and the q-axis inductance are approximately equal $\left(L_{d}=L_{q}\right)$ in surface permanent magnet synchronous motor (SPMSM)[27].

\section{B. Conventional FCS-MPC current control of PMSM}

Assuming sampling time is $T_{s}$, the stator current derivatives can be discretized using the Euler approximation method, that is:

$$
\frac{d i}{d t} \approx \frac{i(k+1)-i(k)}{T_{s}}
$$

Replacing (2) into (1), d-q axis predictive stator currents in the next sampling time can be obtained as:
$\left\{\begin{array}{l}i_{d}^{p}(k+1)=\left(1-\frac{R_{s} T_{s}}{L_{d}}\right) i_{d}(k)+\frac{T_{s} L_{q}}{L_{d}} \omega_{e} i_{q}(k)+\frac{T_{s}}{L_{d}} u_{d}(k) \\ i_{q}^{p}(k+1)=\left(1-\frac{R_{s} T_{s}}{L_{q}}\right) i_{q}(k)-\frac{T_{s} L_{d}}{L_{q}} \omega_{e} i_{d}(k)-\psi_{m} \omega_{e} T_{s}+\frac{T_{s}}{L_{q}} u_{q}(k)\end{array}\right.$

Where, $i_{d}^{p}(k+1)$ and $i_{q}^{p}(k+1)$ represent the $\mathrm{d}-\mathrm{q}$ axis predictive stator currents in next sampling time; $T_{s}$ is the sampling time. The field-oriented control (FOC) scheme of PMSM current control using FCS-MPC strategy is shown in Fig.3. Here, a PI speed controller is used to generate the qaxis reference current. The FCS-MPC current controller is used for tracking the $d-q$ axis reference currents. The discretetime model of PMSM is used to predict the stator current. During each sampling period, one voltage vector that minimizes the cost function is selected from the nineteen basic voltage vectors and applied to the three-level NPC inverter.

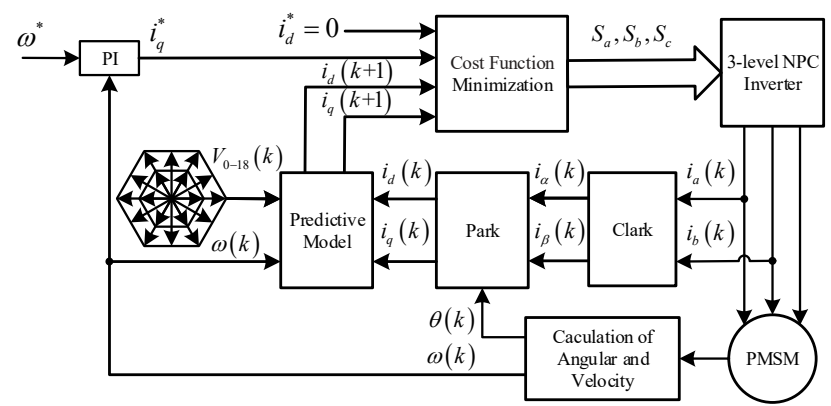

Fig. 3. Control diagram of classical MPC current control method with threelevel NPC inverter.

The cost function can be shown as follow:

$$
g=\left(i_{d}^{p}(k+1)\right)^{2}+\left(i_{q}^{*}-i_{q}^{p}(k+1)\right)^{2}+\hat{f}\left(i_{d}^{p}(k+1), i_{q}^{p}(k+1)\right)
$$

Where, $g$ is the cost function; $i_{q}^{*}$ is the reference value of q-axis current, which is output by PI controller of speed loop; $\hat{f}\left(i_{d}^{p}(k+1), i_{q}^{p}(k+1)\right)$ is restriction of $\mathrm{d}$-q axis currents, it can be shown as follow:

$$
\hat{f}\left(i_{s d}^{p}(k+1), i_{s q}^{p}(k+1)\right)= \begin{cases}\infty & \text { if }\left|i_{s d}^{p}\right|>i_{\max } \text { or }\left|i_{s q}^{p}\right|>i_{\max } \\ 0 & \text { if }\left|i_{s d}^{p}\right| \leq i_{\max } \text { and }\left|i_{s q}^{p}\right| \leq i_{\max }\end{cases}
$$

The task of the FCS-MPC strategy is selected the optimal switching state, which executes nineteen times (each for different basic voltage vector) to calculate the optimal cost function.

\section{Modulated Model Predicative CURRENT CONTROL FOR PMSM}

Same as the conventional MPC strategy, M2PC also has prediction and optimization sections. The cost function $g$ is evaluated for each case. The only difference is the M2PC includes a suitable modulation scheme. The M2PC strategy select two adjacent active voltage vectors which minimize the cost function in each sector at every sampling time. The FOC control scheme of PMSM current control with three-level NPC inverter using M2PC strategy is shown in Fig.4. For example, two adjacent voltage vector $\mathbf{v}_{1}$ and $\mathbf{v}_{2}$ are selected in the first sector. Each prediction is calculated based on (3) and (4). $g_{1}, g_{2}, g_{0}$ are cost functions of voltage vectors $\mathbf{v}_{1}, \mathbf{v}_{2}$ and zero voltage vector, respectively. As shown in (6). The duty 
cycles of two adjacent active voltage vectors $\mathbf{v}_{1}, \mathbf{v}_{2}$ and zero voltage vector are calculated respectively.

$$
\begin{aligned}
& d_{0}=K / g_{0} \\
& d_{1}=K / g_{1} \\
& d_{2}=K / g_{2} \\
& T_{s}=d_{0}+d_{1}+d_{2}
\end{aligned}
$$

Where $d_{0}, d_{1}, d_{2}$ correspond to the duty cycles of zero voltage vector and two adjacent active voltage vectors $\mathbf{v}_{1}, \mathbf{v}_{2}$. From (6), duty cycles for each vector and the parameter $K$ can be calculated as follows:

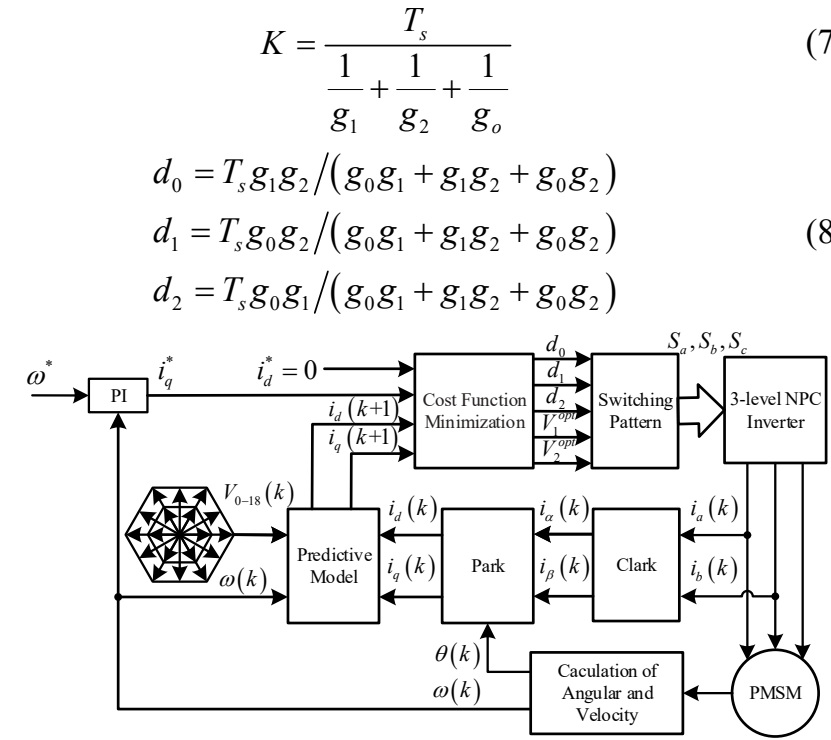

Fig. 4. Control diagram of M2PC current control method with three-level NPC inverter.

With these above equations, the total cost function $g$ is defined as follow:

$$
g=d_{1} g_{1}+d_{2} g_{2}
$$

The minimum total cost function $g$, which is evaluated by two active voltage vectors, is applied to the three-level NPC inverter in the next sampling period.

\section{Simulation Results}

To verify the performance of M2PC strategy, a simulation model is built in Matlab2018a. The parameters of the simulation are listed in table II. The simulation step is $1 \mathrm{e}-6$, the current loop sampling time is 50e-6, the speed loop sampling time is same as the current loop. The speed controller is a PI controller, the proportion parameter is 0.009 , and the integral parameter is 1.2. Both classical MPC strategy and proposed M2PC are evaluated in simulation.

The initial load of PMSM is $0.2 \mathrm{~N}$.m and target speed of PMSM is $1800 \mathrm{rpm}$. In order to verify transient performance of the PMSM system, the load increases to $0.5 \mathrm{~N}$.m suddenly in $0.05 \mathrm{~s}$.

The waveforms of the $\mathrm{d}-\mathrm{q}$ axis currents responses by classical MPC and M2PC are shown in Fig.5 and 6, respectively. It can be observed that the load increased suddenly at $0.05 \mathrm{~s}$, the q-axis current can response quickly. M2PC has a higher switching frequency than classical MPC in the same DSP interrupt time 50e-6, therefore, classical MPC strategy has a bigger ripple than M2PC strategy in the same sample time. The current THD of both methods will be discussed in details in Fig.13 and 14.
TABLE II

PARAMETER SETTING OF THE SIMULATION

\begin{tabular}{ccc}
\hline \hline Parameter & Symbol & Value \\
\hline Rated Voltage & $V$ & $36 \mathrm{~V}$ \\
Rated Current & $I$ & $4.6 \mathrm{~A}$ \\
Maximum Current & $I_{\max }$ & $13.8 \mathrm{~A}$ \\
Rated Power & $P$ & $100 \mathrm{~W}$ \\
Rated Torque & $T$ & $0.318 \mathrm{~N} \cdot \mathrm{m}$ \\
Stator Phase Resistance & $R$ & $0.375 \mathrm{Ohm}$ \\
Motor Inertia & $J$ & $0.0588 \mathrm{~kg} \cdot \mathrm{m}^{2} .10^{-4}$ \\
Pole Pairs & $P_{n}$ & $4 \mathrm{Pair}$ \\
q-axis Inductance & $L_{q}$ & $0.001 \mathrm{H}$ \\
d-axis Inductance & $L_{d}$ & $0.001 \mathrm{H}$ \\
Simulation Time & $T_{m}$ & $1 \mathrm{e}-6 \mathrm{~s}$ \\
Sampling Time & $T_{s}$ & $50 \mathrm{e}-6 \mathrm{~s}$ \\
Switching frequency & $f_{s}$ & $20 \mathrm{kHz}$ \\
Incremental Encoder Lines & $N$ & $2500 \mathrm{PPR}$ \\
\hline
\end{tabular}

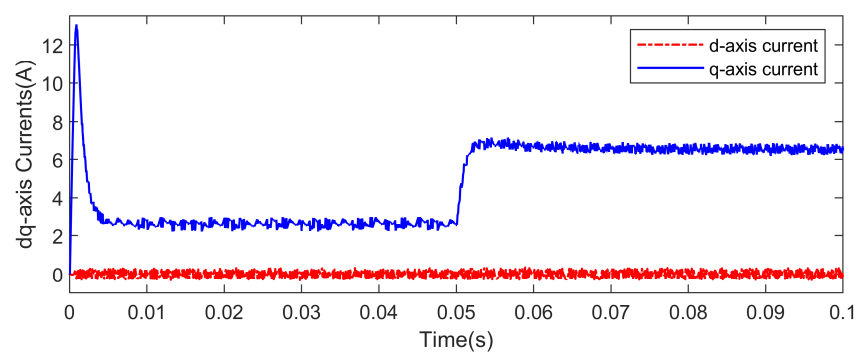

Fig. 5. d-q axis currents responses under classical MPC current control strategy in the presence of load torque disturbance at $1800 \mathrm{rpm}$.

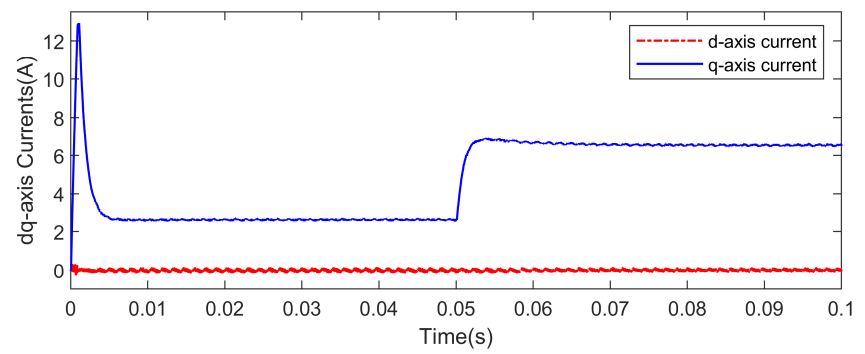

Fig. 6. d-q axis currents responses under M2PC current control strategy in the presence of load torque disturbance at $1800 \mathrm{rpm}$.

Fig. 7 and Fig. 8 show the waveforms of the three phase currents for the classical MPC and M2PC, respectively. As evident, the M2PC shows lower ripple than the classical MPC. The step response of the PMSM for both methods is shown in Fig. 9 and Fig. 10, observing again, a better performance of the speed for the M2PC strategy. It can be observed that the speed of PMSM decrease as the load increased in $0.05 \mathrm{~s}$, then it can restore to target speed very quickly. However, the speed fluctuation of classical MPC strategy is bigger than M2PC strategy. Similarly, Fig. 11 and Fig. 12 show the line voltages for classical MPC and M2PC. FFT analysis for the A phase current under classical MPC strategy and M2PC strategy are shown in Fig.13 and 14. The fundamental frequency is $120 \mathrm{~Hz}$, A phase current is analyzed in two cycles. It can be seen from the Fig. 13 and 14, classical MPC strategy has a higher THD value than M2PC strategy in the same sample time 50e-6. The M2PC has a higher switching frequency than classical MPC. 


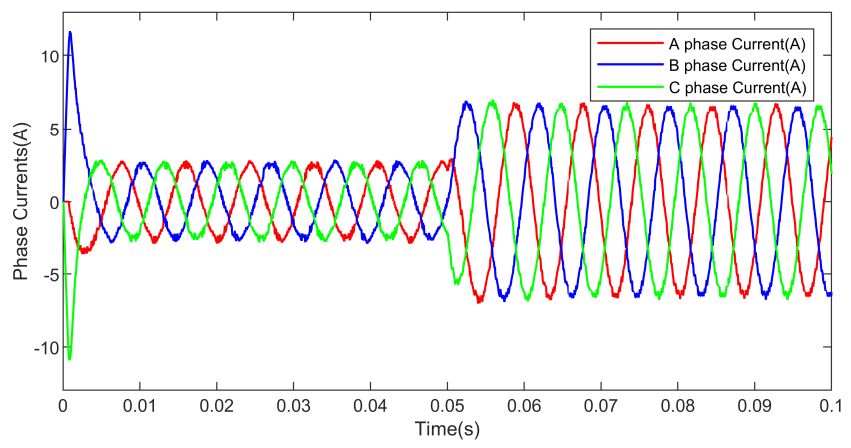

Fig. 7. Phase currents responses under classical MPC current control strategy in the presence of load torque disturbance at $1800 \mathrm{rpm}$.

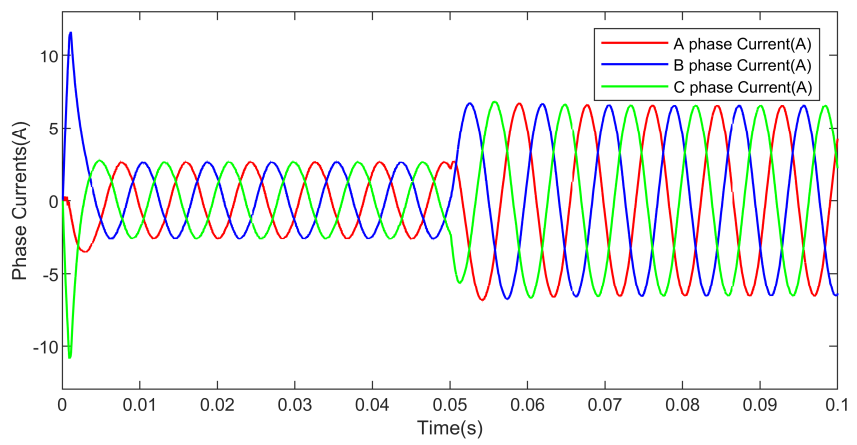

Fig. 8. Phase currents responses under M2PC current control strategy in the presence of load torque disturbance at 1800rpm.

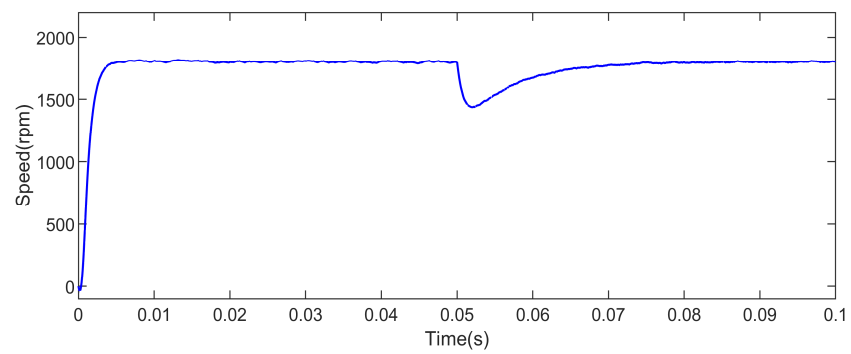

Fig. 9. Speed response under classical MPC current control strategy in the presence of load torque disturbance at 1800rpm.

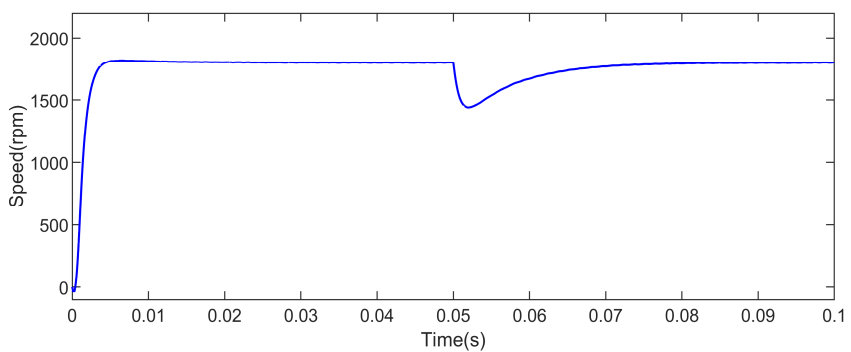

Fig. 10. Speed response under M2PC current control strategy in the presence of load torque disturbance at $1800 \mathrm{rpm}$.

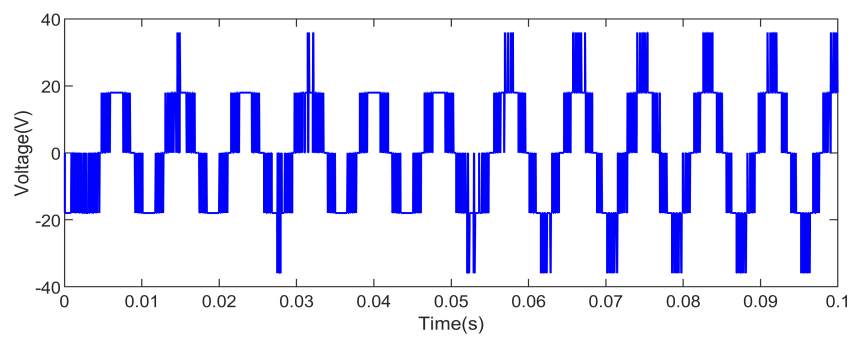

Fig. 11. Line voltage of inverter by classical MPC current control strategy.

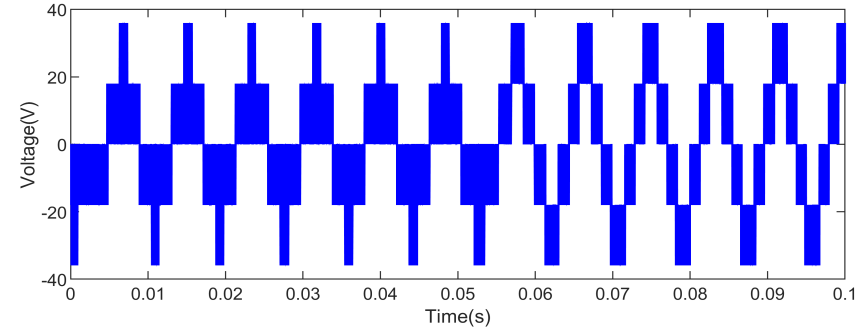

Fig. 12. Line voltage of inverter by M2PC current control strategy.

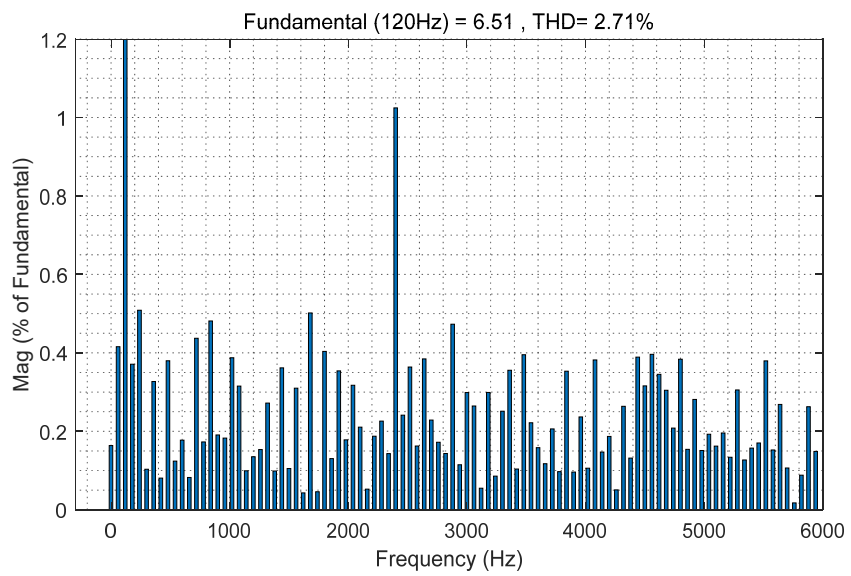

Fig. 13. FFT analysis for the A phase current by classical MPC strategy.

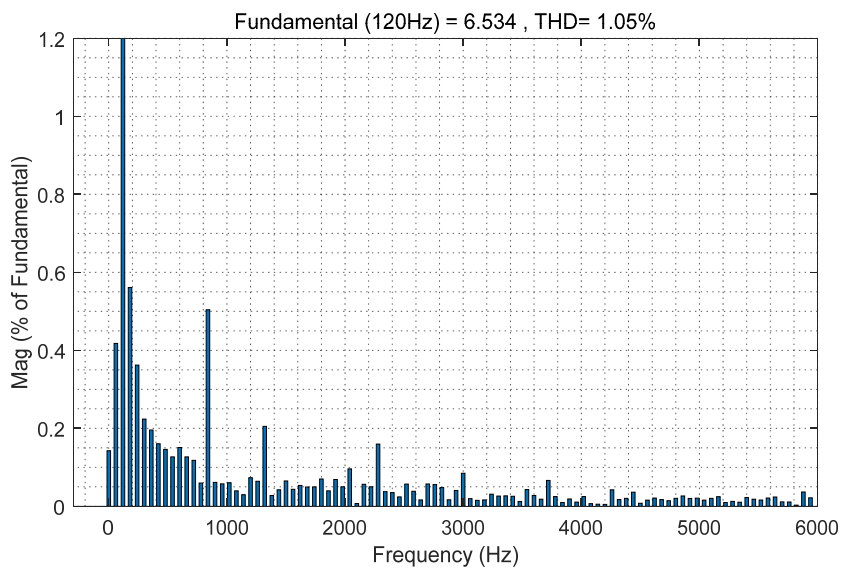

Fig. 14. FFT analysis for the A phase current by M2PC strategy.

\section{CONCLUSIONS}

A M2PC strategy for a three-level NPC inverter feeding a PMSM was proposed in this paper. Compared with the classical MPC strategy, the proposed M2PC strategy produced a modulated waveform to reduce the THD value, and has a smaller current and torque ripple. The simulation was implemented in Matlab2018a, and the results show the feasibility and effectiveness of M2PC strategy.

\section{ACKNOWLEDGMENT}

The authors would like to thank the financial support of the Clean Sky 2 Joint Undertaking under Grant 807081 and the Fondecyt Regular Project 1160690.

\section{REFERENCES}

[1] S. Janous, D. Janik, T. Kosan, P. Kamenický, and Z. Peroutka, "Comparative study of vector PWM and FS-MPC for 3-level Neutral Point Clamped converter," in Proceedings of the 16th International Conference on Mechatronics - Mechatronika 2014, 2014, pp. 158-163. 
[2] M. Rivera et al., "Modulated Model Predictive Control (M2PC) with fixed switching frequency for an NPC converter," in 2015 IEEE 5th International Conference on Power Engineering, Energy and Electrical Drives (POWERENG), Riga, Latvia, 2015, pp. 623-628.

[3] J. Rodriguez, S. Bernet, P. K. Steimer, and I. E. Lizama, "A Survey on Neutral-Point-Clamped Inverters," IEEE Transactions on Industrial Electronics, vol. 57, no. 7, pp. 2219-2230, Jul. 2010.

[4] "Model Predictive Control," in Predictive Control of Power Converters and Electrical Drives, Chichester, UK: John Wiley \& Sons, Ltd, 2012, pp. 31-39.

[5] S. Kouro, P. Cortes, R. Vargas, U. Ammann, and J. Rodriguez, "Model Predictive Control-A Simple and Powerful Method to Control Power Converters," IEEE Transactions on Industrial Electronics, vol. 56, no. 6, pp. 1826-1838, Jun. 2009.

[6] H. Miranda, P. Cortes, J. I. Yuz, and J. Rodriguez, "Predictive Torque Control of Induction Machines Based on State-Space Models," IEEE Transactions on Industrial Electronics, vol. 56, no. 6, pp. 1916-1924, Jun. 2009.

[7] J. Rodriguez et al., "State of the Art of Finite Control Set Model Predictive Control in Power Electronics," IEEE Transactions on Industrial Informatics, vol. 9, no. 2, pp. 1003-1016, May 2013.

[8] S. Vazquez et al., "Model Predictive Control: A Review of Its Applications in Power Electronics," IEEE Industrial Electronics Magazine, vol. 8, no. 1, pp. 16-31, Mar. 2014.

[9] M. Rivera et al., "A Comparative Assessment of Model Predictive Current Control and Space Vector Modulation in a Direct Matrix Converter," IEEE Transactions on Industrial Electronics, vol. 60, no. 2, pp. 578-588, Feb. 2013.

[10] T. Geyer and S. Mastellone, "Model Predictive Direct Torque Control of a Five-Level ANPC Converter Drive System," IEEE Transactions on Industry Applications, vol. 48, no. 5, pp. 1565-1575, Sep. 2012.

[11] V. Yaramasu and B. Wu, "Predictive Control of a Three-Level Boost Converter and an NPC Inverter for High-Power PMSG-Based Medium Voltage Wind Energy Conversion Systems," IEEE Transactions on Power Electronics, vol. 29, no. 10, pp. 5308-5322, Oct. 2014.

[12] Y. Yang, H. Wen, M. Fan, M. Xie, and R. Chen, "Fast FiniteSwitching-State Model Predictive Control Method Without Weighting Factors for T-Type Three-Level Three-Phase Inverters," IEEE Transactions on Industrial Informatics, vol. 15, no. 3, pp. 1298-1310, Mar. 2019.

[13] Y. Zhang and H. Yang, "Two-Vector-Based Model Predictive Torque Control Without Weighting Factors for Induction Motor Drives," IEEE Transactions on Power Electronics, vol. 31, no. 2, pp. 1381-1390, Feb. 2016.

[14] P. Kakosimos and H. Abu-Rub, "Deadbeat Predictive Control for PMSM Drives With 3-L NPC Inverter Accounting for Saturation Effects," IEEE Journal of Emerging and Selected Topics in Power Electronics, vol. 6, no. 4, pp. 1671-1680, Dec. 2018.

[15] A. D. Alexandrou, N. K. Adamopoulos, and A. G. Kladas, "Development of a Constant Switching Frequency Deadbeat Predictive Control Technique for Field-Oriented Synchronous Permanent-Magnet
Motor Drive," IEEE Transactions on Industrial Electronics, vol. 63, no. 8, pp. 5167-5175, Aug. 2016.

[16] Y. Jiang, W. Xu, C. Mu, and Y. Liu, "Improved Deadbeat Predictive Current Control Combined Sliding Mode Strategy for PMSM Drive System," IEEE Transactions on Vehicular Technology, vol. 67, no. 1, pp. 251-263, Jan. 2018.

[17] X. Zhang, B. Hou, and Y. Mei, "Deadbeat Predictive Current Control of Permanent-Magnet Synchronous Motors with Stator Current and Disturbance Observer," IEEE Transactions on Power Electronics, vol. 32, no. 5, pp. 3818-3834, May 2017.

[18] L. Tarisciotti, P. Zanchetta, A. Watson, J. C. Clare, M. Degano, and S. Bifaretti, "Modulated Model Predictive Control for a Three-Phase Active Rectifier," IEEE Transactions on Industry Applications, vol. 51, no. 2, pp. 1610-1620, Mar. 2015.

[19] L. Tarisciotti, P. Zanchetta, A. Watson, S. Bifaretti, and J. C. Clare, "Modulated model predictive control for a seven-level cascaded hbridge back-to-back converter," IEEE Transactions on Industrial Electronics, vol. 61, no. 10, pp. 5375-5383, 2014.

[20] L. Tarisciotti, P. Zanchetta, A. Watson, P. Wheeler, J. C. Clare, and S. Bifaretti, "Multiobjective Modulated Model Predictive Control for a Multilevel Solid-State Transformer," IEEE Transactions on Industry Applications, vol. 51, no. 5, pp. 4051-4060, Sep. 2015.

[21] X. Li et al., "A Modulated Model Predictive Control Scheme for the Brushless Doubly Fed Induction Machine," IEEE Journal of Emerging and Selected Topics in Power Electronics, vol. 6, no. 4, pp. 1681-1691, Dec. 2018.

[22] F. Donoso, A. Mora, R. Cárdenas, A. Angulo, D. Sáez, and M. Rivera, "Finite-Set Model-Predictive Control Strategies for a 3L-NPC Inverter Operating With Fixed Switching Frequency," IEEE Transactions on Industrial Electronics, vol. 65, no. 5, pp. 3954-3965, May 2018.

[23] A. R. Beig, G. Narayanan, and V. T. Ranganathan, "Modified SVPWM Algorithm for Three Level VSI With Synchronized and Symmetrical Waveforms," IEEE Transactions on Industrial Electronics, vol. 54, no. 1, pp. 486-494, Feb. 2007.

[24] X. Gao, W. Tian, X. Liu, Z. Zhang, and R. Kennel, "Model Predictive Control of a Three-Level NPC Rectifier with a Sliding Manifold Term,' in 2018 International Power Electronics Conference (IPEC-Niigata 2018 -ECCE Asia), Niigata, 2018, pp. 1661-1665.

[25] B. A. Welchko, M. B. de Rossiter Correa, and T. A. Lipo, "A ThreeLevel MOSFET Inverter for Low-Power Drives," IEEE Transactions on Industrial Electronics, vol. 51, no. 3, pp. 669-674, Jun. 2004.

[26] W.-S. Oh, S.-K. Han, S.-W. Choi, and G.-W. Moon, "Three Phase Three-Level PWM Switched Voltage Source Inverter With Zero Neutral Point Potential," IEEE Transactions on Power Electronics, vol. 21, no. 5, pp. 1320-1327, Sep. 2006.

[27] A. Al-Janabi, Vector Control Of Permanent Magnet Synchronous Motor: LEARN Types of Motors and Application. The PMSM motor Applications. MATLAB simulation of PMSM with vector control idea. LAP LAMBERT Academic Publishing, 2016. 